\title{
BREEDING SEASON, LENGTH-WEIGHT RELATIONSHIP AND CONDITION FACTOR OF INTRODUCED FISH, TILAPIA ZILLII GERVAIS 1948 (PISCES: CICHLIDAE) IN LAKE ZWAI, ETHIOPIA
}

\author{
Alemayehu Negassa and Abebe Getahun* \\ Department of Biology, Faculty of Science, Addis Ababa University, PO Box 1176 \\ Addis Ababa, Ethiopia. E-mail: abebeg@bio.aau.edu.et
}

\begin{abstract}
Breeding season, length-weight relationship and condition factor of Tilapia zillii were studied in Lake Zwai from samples collected over 12 months between January and December, 2001 using gillnets of 60 and $100 \mathrm{~mm}$ stretched mesh. State of gonad maturation and Gonadosomatic index (GSI) values showed that $T$. zillii in Lake Zwai breeds all year round with peak activities between April and September. The relationship between total length (TL) $(5.5-32 \mathrm{~cm})$ and total weight $(\mathrm{TW})(3.8-676.9$ g) of the fish was found to be curvilinear and represented as TW $=0.02 \mathrm{TL}^{2.9813}, \mathrm{R}^{2}=0.99, \mathrm{P}<0.001, \mathrm{n}=$ 848. Mean monthly Fulton condition factors (FCF) and Relative condition factors (RCF) of the population of T. zillii were 2.06 and 1.01, respectively. Two factor ANOVA indicated a significant seasonal fluctuation $(p<0.001)$ in the condition of both sexes, but not between female and male T. zillii $(p=0.127$ and 0.135 for FCF and RCF, respectively). Poor body conditions coincided with time of peak breeding activity. The interaction effects of sex and month on Fulton's and Relative condition factors were not significant $(\mathrm{p}=0.127$ and 0.138 respectively).
\end{abstract}

Key words/phrases: Breeding season, Ethiopia, Lake Zwai, length-weight relationship, Tilapia zillii

\section{INTRODUCTION}

Tilapia zillii was introduced into various water bodies of Ethiopia including Lake Zwai. The fish was originally imported from Uganda and introduced into Lake Zwai in 1975 (Shibru Tedla and Fisseha H. Meskel, 1981). Since then it has successfully established itself and become an important component of the commercial catch (pers. obs.). However, catch per unit effort records of $T$. zillii were non-existent during the study period probably because it was confused with the related Oreochromis niloticus, or since fishing is focused in the pelagic zone where T. zillii is rare or absent as the target of fishermen was mainly $O$. niloticus which has wider acceptance.

It is a polyphilic and euryhaline species, widely distributed from west Africa to the Nile basin and is a resident of Lakes Albert and Turkana (Trewavas, 1982). T. zillli is a monogamous biparental guarder (El-Zarka, 1956), and it is known to breed throughout the year in equatorial waters including Lakes Naivasha (Siddiqui, 1977, 1979) and Victoria (Welcomme, 1967). However, in Lake Quarun (a subtropical region) spawning in the fish is limited to 5 months (May to September) with a highest rate of breeding in mid-summer (July and August) (El-Zarka, 1962). There are no data on the biology of the species in Ethiopian waters (Abebe Getahun and Stiassny, 1998). The present study was, therefore, conducted to examine the breeding season, length-weight relationship and condition factor of T. zillii in Lake Zwai. This information is undoubtedly vital for proper management and development of culture fisheries in the country.

\section{Study area: Lake Zwai}

Lake Zwai with a surface area of $434 \mathrm{~km}^{2}$ and mean depth of $2.5 \mathrm{~m}$ (Schroder, 1984), is the most northerly of the upper rift natural lakes in the country located at $7^{\circ} 52^{\prime}-8^{\circ} 8^{\prime} \mathrm{N}$ Latitude and $38^{\circ}$ $40^{\prime}-38^{\circ} 56^{\prime} \mathrm{E}$ Longitude, and lies at an altitude of $1636 \mathrm{~m}$ (Makin et al., 1975). The lake is fed by a number of rivers of which Meki and Katar are the major ones and drains south via the Bulbula River.

The lake lies in a region characterized by semiarid climate. The climatic condition of the region is fairly constant as the mean daily air temperature ranges between $15.37( \pm 0.97)$ and $27.38( \pm 0.38)^{\circ} \mathrm{C}$ (Fig. 1). However, variations have been noted with the rainy and dry seasons. Peak rains occurred in May, July and August; a small rain in March, while the months between October and February were generally dry (Fig. 1a).

\footnotetext{
* Author to whom correspondence should be addressed.
} 
The fish community of the lake is composed of both native and introduced species. The native species comprise $O$. niloticus and some Barbus species whereas the introduced ones are T. zillii,
Clarias gariepinus and Carassius auratus. The potential yield of the Lake fishery is estimated in the range of 1000 to 6000 tones per year (LFDP, 1998).
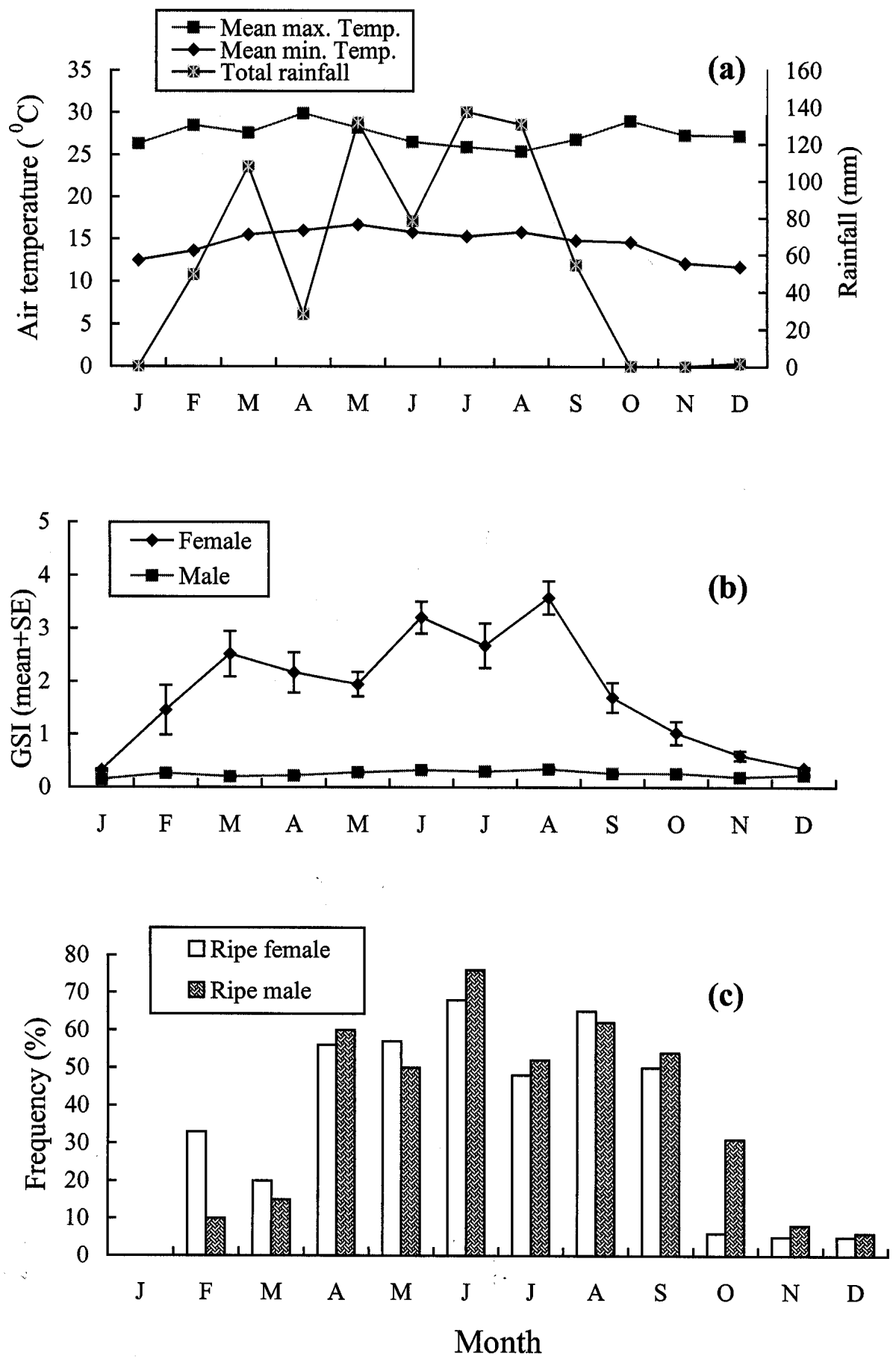

Fig. 1. Monthly mean minimum and maximum temperature and total rainfall around Lake Zwai during the year 2001 (a), Seasonal variation in Gonadosomatic index of female and male T. zillii (b) and Frequency of ripe female and male gonads of T. zillii (c). 


\section{MATERIALS AND METHODS}

Adult fish samples of $T$. zillii ranging in length between 12.5 and $32 \mathrm{~cm}$ were collected over a twelve months period during the year 2001 using gill nets (60 and $100 \mathrm{~mm}$ stretched mesh) from the two sampling sites. Sampled fish were taken to the Zwai Fisheries Resources Development Research Centre laboratory soon after capture. In the laboratory, total length (TL) and total weight (TW) of all specimens were measured to the nearest 0.1 $\mathrm{cm}$ and $0.1 \mathrm{~g}$ using a measuring board and sensitive balance (EK-1200A), respectively. Each adult specimen was sexed by visual examination of the gonads and the stage of gonad maturation was determined following a five stage maturity keys of El-Zarka (1962). The percentage of ripe fish was computed considering stage IV. Each gonad was also weighed to the nearest $0.1 \mathrm{~g}$.

Breeding season of T. zillii was determined based on the frequency of the various gonad stages identified and gonadosomatic index (GSI) values. GSI was calculated as gonad weight in percent of total body weight (including the gonads).

$$
G S I=\frac{\text { Gonad } w t}{\text { Body } w t} \times 100
$$

The percentage frequency of breeding fish and GSI were then plotted by month. The time of the year when the frequency and GSI were high was considered as the peak-breeding season for the fish. Length-weight relationship and condition factor of T. zillii were computed from the total weight (TW) and total length (TL) measurements following the procedures employed by Le Cren (1951) and Bagenal and Tesch (1978). Accordingly, the length-weight relationship was calculated using least square regression analysis and Fulton and Relative condition factors as follows:

a) Fulton condition factor $(\mathrm{FCF})=100 \mathrm{~T}^{*} \mathrm{~W}^{*} \mathrm{TL}^{-3}$

b) Relative condition factor (RCF) $=\mathrm{TW} / a \mathrm{TL}^{b}$

where, $a$ and $b$ are the intercept and slope of the length-weight regression, respectively. The condition factor of individual fish was calculated and monthly mean values were determined for the sexes separately.

\section{RESULTS}

\section{Breeding season}

Monthly variation in GSI of both female and male T. zillii was evident (Fig. 1-b). The mean monthly GSI \pm SE of females ranged from $0.32 \pm 0.02$ (in January) to $3.58 \pm 0.31$ (in August) and that of males ranged from $0.15 \pm 0.02$ (in January) to $0.34 \pm$ 0.04 (in August). GSI values were high from February to September and low between October and January.

The percentage of ripe female and male T. zillii ranged from $5-68 \%$ and $6-76 \%$, respectively with high percentage values between April and September (Fig. 1-c). From the above observations, it is evident that T. zillii in Lake Zwai breeds almost continuously throughout the year, with peak months between April and September.

\section{Length-weight relationship and condition factor}

The Length-weight relationship of female and male T. zillii in Lake Zwai was curvilinear and best described by the following regression equations.

Females: $\mathrm{TW}=0.0299 \mathrm{TL} 2.8768, \quad \mathrm{R}^{2}=0.9502, \mathrm{n}=309$ Males: $\quad \mathrm{TW}=0.0271 \mathrm{TL}^{2.9041}, \quad \mathrm{R}^{2}=0.9487, \mathrm{n}=394$

Comparison of the above two equations showed no significant difference in length-weight relationship between the sexes (ANOVA, $\mathrm{p}>0.05$ ). Therefore, an equation common to the sexes and the young ones was fitted to data of 848 fish ranging in length between 5.5 and $32.0 \mathrm{~cm}$ and total weight between 3.8 and 676.9 g. The relationship was curvilinear with a slope $(b=2.98 \pm 0.05)$ very close to the theoretical value $b=3$ (Fig. 2). Values of the slopes determined separately for the sexes as well as the common slope are significantly different from zero (ANOVA, $\mathrm{p}<$ 0.001).

Monthly Fulton's condition factor (mean $\pm \mathrm{SE}$ ) values of T. zillii in Lake Zwai ranged from $1.93 \pm$ 0.06 in April to $2.38 \pm 0.30$ in January for females and from $1.88 \pm 0.04$ in April to $2.41 \pm 0.1$ in March for males (Fig. 4A). Mean FCF \pm SE was found to be $2.08 \pm 0.03$ for females, $2.05 \pm 0.01$ for males and $2.06 \pm 0.01$ for both sexes in general. FCF varied significantly among months in both sexes (ANOVA, $p<0.001)$, but not between females and males ( $p=$ $0.127)$. 


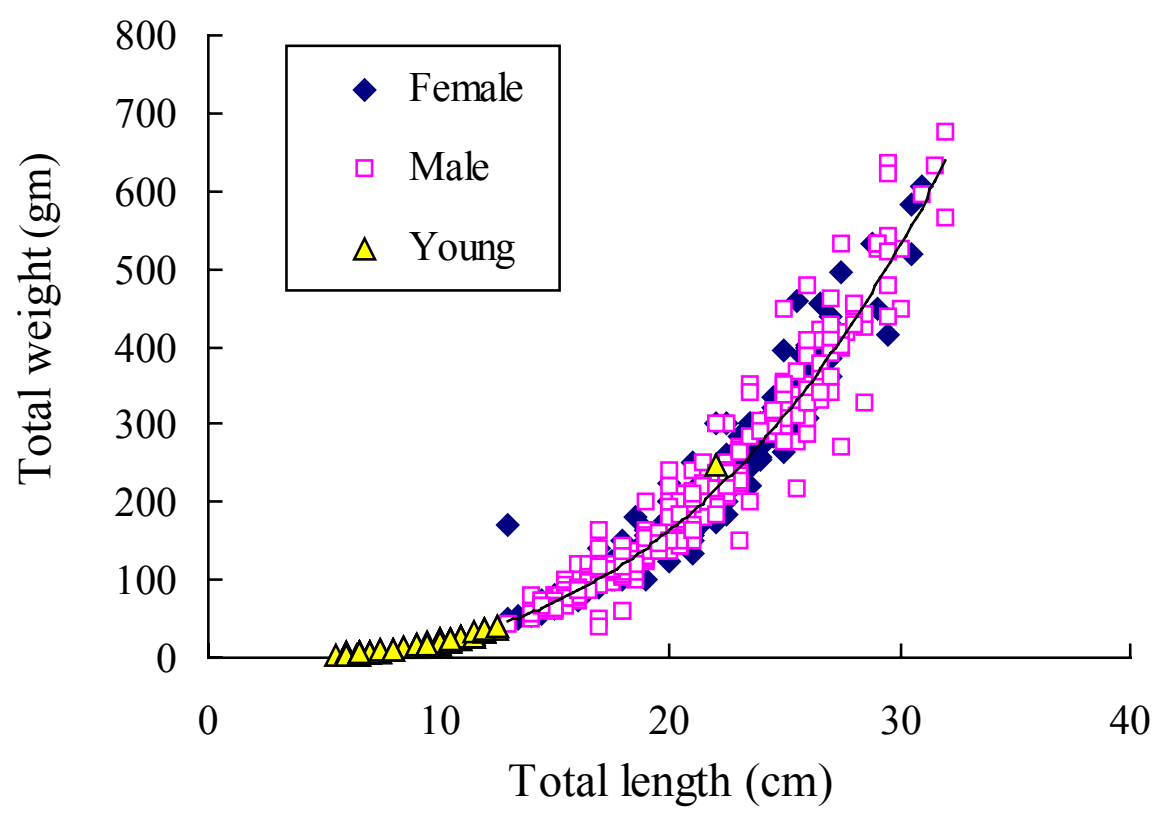

Fig. 2. Length-weight relationship of T. $z$ illii in Lake Zwai. (TW $=0.0216 \mathrm{TL} 2.9813, \mathrm{R} 2=0.99 \mathrm{n}=848$ ).

Monthly mean Relative condition factor $(\mathrm{RCF} \pm$ $\mathrm{SE})$ values of $T$. zillii ranged from $1.03 \pm 0.03$ in April to $1.26 \pm 0.16$ in January for females and from $1.00 \pm 0.02$ in April to $1.28 \pm 0.05$ in March for males (Fig. 4B). Mean RCF \pm SE was found to be 1.10 \pm 0.01 for females, $1.09 \pm 0.01$ for males and $1.10 \pm$ 0.01 for both sexes. RCF values were significantly different (ANOVA, $\mathrm{p}<0.001$ ) between months in both sexes, but not between females and males $(p=$ 0.135). The interaction effect of sex and month on the relative condition factor of the fish was not significant $(p=0.907)$.

\section{DISCUSSION}

The study showed that the population of T. zillii in Lake Zwai is characterized by an overall preponderance of males. Sex ratio in favor of males has also been reported for the species from Lake Quaraun (El-Zarka, 1962). In samples collected during January, March and July the proportion was equal or nearly equal to that of females and in May the proportion is slightly less (Table 1). However, in samples collected during the remaining months males outnumbered females. From the present study it was not possible to give a definite explanation for the biased sex ratio.
Nevertheless, studies on other species have suggested sex reversal (Hughes, 1992), activity difference between sexes during spawning and the type of gear and sampling site used (Demeke Admassu, 1994), as possible causes of biased sex ratio.

In T. zillii, seasonal variations in GSI and the percentage of ripe fish (Figs. 1-b and 1-c) were quite apparent and the pattern was more or less similar in both sexes. Indeed, fish with welldeveloped gonads and ripe eggs were noted almost throughout the year. GSI values and percentage of ripe fish indicated that breeding in $T$. zillii was year round peaking from April to September. Zenebe Tadesse (1988) also reported that the related species, $O$. niloticus in the same study area reproduces continuously throughout the year with a high peak of activity between December and March. The presence of individual breeding fish in Lake Zwai at all times of the year may be partly attributed to the low seasonal fluctuations in temperature (Fig. 1-a). LoweMcConnell (1982) also stated that in the tropics seasonal fluctuations in temperature and photoperiod are generally very low and this might be favorable for fish species to spawn at any time of the year. 
Table 1. Number of male and female, and sex-ratio (M:F) of T. zillii in monthly samples collected from Lake Zwai during the year 2001. ${ }^{*}=$ significant at $5 \%$ level $)$.

\begin{tabular}{lcccc}
\hline \multicolumn{1}{c}{ Month } & Male & Female & Sex-ratio & Chi-square \\
\hline January & 21 & 19 & $1: 0.90$ & 0.10 \\
February & 30 & 12 & $1: 0.40$ & $7.71^{*}$ \\
March & 20 & 20 & $1: 1$ & 0.00 \\
April & 27 & 16 & $1: 0.59$ & 2.81 \\
May & 22 & 28 & $1: 1.27$ & 0.72 \\
June & 35 & 28 & $1: 0.80$ & 0.78 \\
July & 25 & 27 & $1: 1.08$ & 0.08 \\
August & 58 & 46 & $1: 0.79$ & 1.38 \\
September & 35 & 30 & $1: 0.86$ & 0.38 \\
October & 45 & 34 & $1: 0.76$ & 1.53 \\
November & 45 & 35 & $1: 0.78$ & 1.25 \\
December & 31 & 14 & $1: 0.45$ & $6.42^{*}$ \\
Total & 394 & 309 & $1: 0.78$ & $10.28^{*}$ \\
\hline
\end{tabular}

The peak reproductive activity of the fish coincided with rainy seasons of the region (Fig. 1). Several authors (e.g., Lowe-McConnell, 1987) have also concluded that breeding among tilapias has a distinct peak just before or at the onset of the rainy season, and agrees well with the present result. With the advent of the rainy season the lake level rises and due to the flooding of land terrestrial nutrients flush into the lake. As a result, habitats and food resources for fish could expand greatly and hence these might trigger reproduction. According to Jalabert and Zohar (1982) increased lake production and rise in water level provides suitable spawning grounds for adults and feeding and nursery grounds for the young. Previous report also confirmed abundance of food as being an important cue for timing of breeding in fish (Mckaye, 1977).

In the present study size of the biggest fish recorded was $32 \mathrm{~cm}$. The biggest size recorded in west Africa is $21 \mathrm{~cm}$ (Teugels and Thys van den Audenaerde, 1992). This suggests that T. zillii can reach bigger size in Lake Zwai environment, which is worth investigating. There was a curvilinear relationship between total length and total weight of T. zillii in Lake Zwai (Fig. 2). The value of the regression coefficient $(b=2.98)$ was close to the theoretical value $(b=3)$ indicating isometric growth of the fish in the lake. The regression equation relating TL and TW of the fish can be used to estimate one variable from the other for those between $5.5 \mathrm{~cm}$ and $32 \mathrm{~cm}$ in TL and $3.8 \mathrm{~g}$ and 676.9 $\mathrm{g}$ in TW.

The value of $b$ for the population of T. zillii with total length between 7 and $15 \mathrm{~cm}$ in Nigeria was found to be 3.21. Comparison of length-weight relationship curves for the populations of T. zillii in Ethiopia and Nigeria shows that the population from Ethiopia are in a better condition than that from Nigeria specially at smaller lengths, that is, the curves for T. zillii populations indicate that for a given length the fish from Ethiopia is heavier than that from Nigeria (Fig. 3). However, the condition of population from Nigeria seems to improve with increasing length.

Condition factors which are used to compare the well-being or fatness of fish are based on the hypothesis that the heavier fish of a given length are in better condition. The pattern of seasonal variation in Fulton's and Relative condition factor of both sexes in T. zillii was similar throughout the year. Condition factor of both sexes of T. zillii (Fig. 4-A and B) in Lake Zwai was significantly different (ANOVA, p < 0.001) in the different months. A study done on the related $O$. niloticus in the same lake by Zenebe Tadesse (1988) also showed similar result. Numerous authors (Le Cren, 1951; Getachew Teferra, 1987; Zenebe Tadesse, 1988; 1997; 1999) agree that such variations could arise due to 
seasonal fluctuations in environmental factors, food supply and quality, feeding rate, degree of parasitization and reproductive activity. From the present study it was clear that poor body conditions (Figs. 4-A and B) coincided with peak breeding activity (Figs. 1-b and c). Zenebe Tadesse (1988) also reported the same for O. niloticus. This may indicate that production of sperms in males and eggs in females during breeding season may drain metabolic energy. Also engagement in breeding activity as well as parental care could possibly suppress somatic growth, as the fish devote less time for feeding during the breeding season.

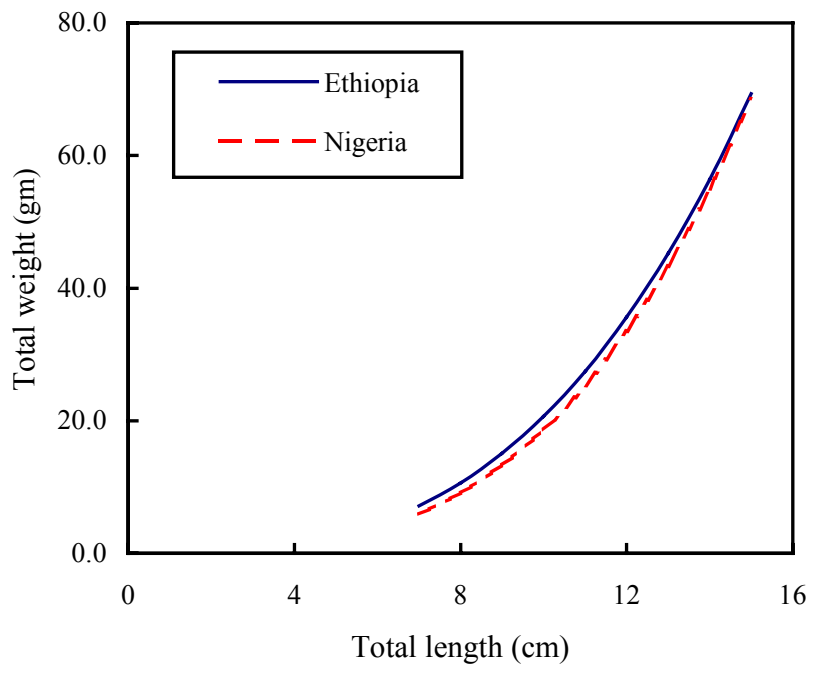

Fig. 3. Comparison of length-weight curves of T.zillii populations from Ethiopia and Nigeria.
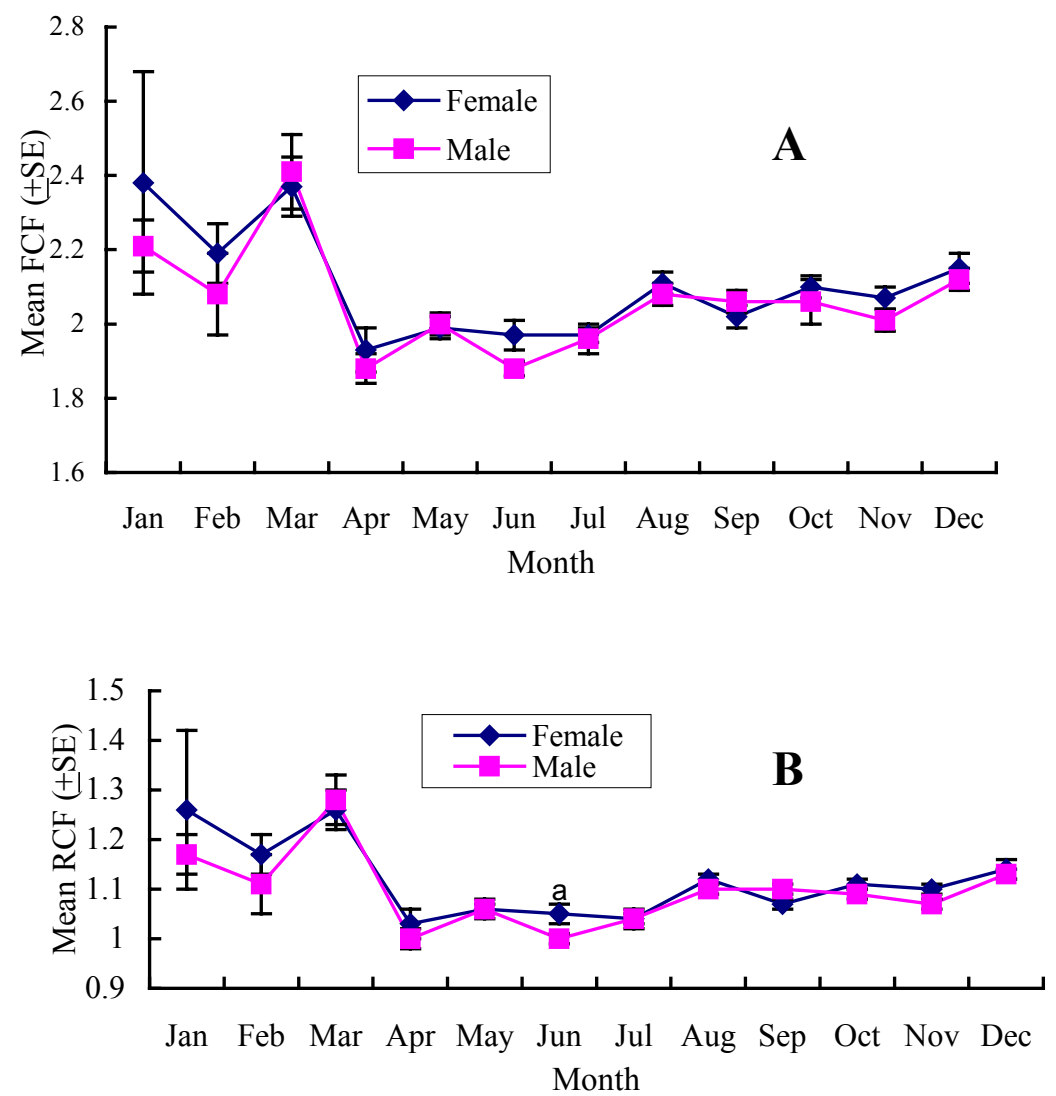

Fig. 4. Monthly Fulton's (A) and Relative (B) condition factor (mean \pm SE) of female and male T. zillii in Lake Zwai for the year 2001. 
Mean FCF of the fish in Lake Zwai was 2.08 for females, 2.05 for males and 2.06 for the population in general. FCF of $T$. zillii population in Lake Victoria, another area of introduction, was found to be 1.9 and reported to be better than that in its native lakes, Rudolf and Albert (Welcomme, 1967). Thus, T. zillii in Lake Zwai was relatively in better condition than that in lakes Victoria, Rudolf and Albert.

In conclusion, in Lake Zwai T. zillii breeds all year round with a high peak of activity between April and September and poor body conditions coincided with peak breeding months. Thus, better exploitation of the fish may be made when breeding is not at its climax during which the fish has better body condition and the capture of breeding ones is minimal.

\section{ACKNOWLEDGEMENTS}

We would like to thank the Swedish Agency for Research and Education for Developing Countries (SAREC) and the Rockefeller Foundation (Grant No. 2001AR 002) for financial support as well as the National Meteorology Services Agency for providing meteorological data. We also extend our sincere thanks to fishermen of Lake Zwai who helped us in sample collection of whom Gezahegn Tilinti and Mulatu Galato deserve special consideration.

\section{REFERENCES}

1. Abebe Getahun and Stiassny, M.L.J. (1998). The freshwater biodiversity crisis: the case of the Ethiopian fish fauna. SINET: Ethiop. J. Sci. 21(2):207-230.

2. Bagenal, T.B. and Tesch, F.W. (1978). Age and growth. In: Methods for Assessment of Fish Production in Freshwater, 3 ${ }^{\text {rd }}$ ed, pp. 101-136, (Bagenal, T., ed.) Blackwell Scientific Publications, Oxford.

3. Demeke Admassu (1994). Maturity, fecundity, brood size and sex ratio of tilapia (Oreochromis niloticus L.) in Lake Awassa. SINET: Ethiop. J. Sci. 17(1):53-69.

4. El-Zarka, S.E. (1956). Breeding behaviour of the Egyptian cichlid fish, Tilapia zillii. Copeia, 2:112-113.

5. El-Zarka, S.E. (1962). Tilapia fisheries investigation in Egyptian lakes III: maturity, spawning and sex ratio of Tilapia zillii (Gerv.) in Lake Quarun. Notes and Memories, No. 67, pp. 1-24. Extension Dept. Editing and Publication Section, Cairo, Egypt.
6. Getachew Teferra (1987). A study on an herbivorous fish (Oreochromis niloticus L) diet and its quality in two Ethiopian rift valley lakes, Awassa and Zwai. J. Fish Biol. 30:439-449.

7. Hughes, N.F. (1992). Growth and reproduction of the Nile perch, Lates niloticus, an introduced predator, in the Nyanza Gulf, Lake Victoria, East Africa. In: Fish Stochs and Fisheries of Lake Victoria: A Hand Book for Field Observations, pp. 318-319, (Witte, F. and Van Densen, W.L.T., eds). Samara Publishing Ltd., London.

8. Jalabert, B. and Zohar, Y. (1982). Reproductive physiology of cichlid fishes, with particular reference to Tilapia and Sarotherodon. In: The Biology and Culture of Tilapias, pp. 129-140, (Pullin, R.S.V. and Lowe McConnell, R.H., eds). Proceedings of the international conference, ICLARM. Manilla, Phillipines.

9. Le Cren, E.D. (1951). The length-weight relationship and seasonal cycle in gonadal weight and condition in the perch (Perca fluviatilis). J. Anim. Ecol. 20:201-219.

10. LFDP (1998). Fisheries Report, Phase II. Animal and Fisheries Resources Development Department(MOA). Addis Ababa, Ethiopia, 61 pp.

11. Lowe-McConnell, R.H. (1982). Tilapias in fish communities. In: The Biology and Culture of Tilapias, pp. 43-83, (Pullin, R.S.V. and Lowe-McConnell, R. H., eds). Proceedings of the international conference, ICLARM. Manilla, Phillipines.

12. Lowe-McConnell, R. H. (1987). Ecological Studies in Tropical Fish Communities. Cambridge University Press. London, New York, 382 pp.

13. Makin, M., Kingham, J.J., Waddam, A.E., Birchal, C.J. and Tamene Tefera (1975). Development projects in the Southern Rift Valley of Ethiopia. Land Resources Study 21. Land Resources Division. Ministry of Overseas Development, England.

14. Mckaye, A.R. (1977). Competition for breeding sites between the cichlid fishes of Lake Jiloa, Nicaragua. Ecology 58:291-302.

15. Schroder, R. (1984). An attempt to estimate the fish stock and sustainable yield of Lake Zwai and Lake Abaya, Ethiopian Rift valley. Arch. Hydrobiologia, Suppl. Bd. 69:411-441.

16. Shibru Tedla and Fisseha H. Meskel (1981). Introduction and transplantation of freshwater fish species in Ethiopia. SINET: Ethiop. J. Sci. 4:69-72.

17. Siddiqui, A.Q. (1977). Reproductive biology, lengthweight relationship and relative condition of Tilapia leucostica (Trewavas) in Lake Naivasha, Kenya. J. Fish Biol., 10:251-260.

18. Siddiqui, A.Q. (1979). Reproductive biology of T. zillii (Gervais) in Lake Naivasha, Kenya. Environ. Biol. Fishes 4:257-262. 
19. Teugels, G.G. and Thys van den Audenaerde, D.F.E. (1992). Cichlidae. In: Faune des poissons d'eaux douces et saumâtres de l'ouest, Tome 2, pp. 714779. ORSTOM/MRAC.

20. Trewavas, E. (1982). Taxonomy and speciation. In: The Biology and Culture of Tilapias, pp. 3-13 (Pullin, R.S.V. and Lowe-McConnell, R.H. eds). Proceedings of the international conference, ICLARM. Manila, Philippines.

21. Welcomme, R.L. (1967). Observations on the biology of the introduced species of tilapia in Lake Victoria. Rev. Zool. Bot. Afr. LXXVI:3-4.
22. Zenebe Tadesse (1988). Studies on some aspects of the biology of Orechromis niloticus L. (Pisces: Cichlidae) in Lake Zwai, Ethiopia. MSc Thesis, School of Graduate Studies, Addis Ababa University, $78 \mathrm{pp}$.

23. Zenebe Tadesse (1997). Breeding season, fecundity, length-weight relationship and condition factor of Oreochromis niloticus L. (Pisces: Cichlidae) in Lake Tana, Ethiopia. SINET: Ethiop. J. Sci. 20(1):31-47.

24. Zenebe Tadesse (1999). The nutritional status and digestibility of Oreochromis niloticus L. in Lake Langano, Ethiopia. Hydrobiologia 416:97-106. 